\title{
Potential Long-Term Health Problems Associated with Ultra-Endurance Running: A Narrative Review
}

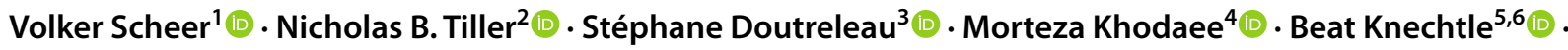 \\ Andrew Pasternak ${ }^{7,8}\left(\right.$ Daniel Rojas-Valverde ${ }^{9}(\mathbb{D}$
}

Accepted: 3 September 2021 / Published online: 20 September 2021

(c) The Author(s), under exclusive licence to Springer Nature Switzerland AG 2021

\begin{abstract}
It is well established that physical activity reduces all-cause mortality and can prolong life. Ultra-endurance running (UER) is an extreme sport that is becoming increasingly popular, and comprises running races above marathon distance, exceeding $6 \mathrm{~h}$, and/or running fixed distances on multiple days. Serious acute adverse events are rare, but there is mounting evidence that UER may lead to long-term health problems. The purpose of this review is to present the current state of knowledge regarding the potential long-term health problems derived from UER, specifically potential maladaptation in key organ systems, including cardiovascular, respiratory, musculoskeletal, renal, immunological, gastrointestinal, neurological, and integumentary systems. Special consideration is given to youth, masters, and female athletes, all of whom may be more susceptible to certain long-term health issues. We present directions for future research into the pathophysiological mechanisms that underpin athlete susceptibility to long-term issues. Although all body systems can be affected by UER, one of the clearest effects of endurance exercise is on the cardiovascular system, including right ventricular dysfunction and potential increased risk of arrhythmias and hypertension. There is also evidence that rare cases of acute renal injury in UER could lead to progressive renal scarring and chronic kidney disease. There are limited data specific to female athletes, who may be at greater risk of certain UER-related health issues due to interactions between energy availability and sex-hormone concentrations. Indeed, failure to consider sex differences in the design of female-specific UER training programs may have a negative impact on athlete longevity. It is hoped that this review will inform risk stratification and stimulate further research about UER and the implications for long-term health.
\end{abstract}

\section{Key Points}

Physical activity is preventative against all-cause mortality, but there is growing evidence that ultra-endurance running (UER) may have pathological implications for multiple body systems.

In susceptible individuals, the most noteworthy maladaptations occur in the cardiovascular system (particularly right ventricular dysfunction), and the renal and musculoskeletal systems.

More epidemiological studies with larger cohorts are needed to better elucidate the complex pathophysiology of long-term health problems in UER.

Volker Scheer

v.scheer@ultrasportsscience.org

Extended author information available on the last page of the article

\section{Introduction}

Ultra-endurance running (UER) can be defined either by running distance (races that exceed the marathon distance of $42.195 \mathrm{~km}$ ) or running time (exceeding $6 \mathrm{~h}$ ), including multi-day or multi-stage events [1]. The popularity of UER has increased over the last 2 decades [2] and, in 2019 alone, over 669,000 runners contested more than 7000 UER events around the world [3]. Participation in UER decreased significantly in 2020 due to the worldwide coronavirus disease 2019 (COVID-19) pandemic [4]. To date, research in UER has focused predominantly on acute injuries and medical problems, as well as physiological, biochemical, nutritional, performance, and training-related aspects [5-11]. More recently, researchers have inquired into the long-term effects of prolonged and strenuous exercise, particularly as UER is one of the most physiologically demanding sports that can potentially lead to long-term health-related issues $[12,13]$. 
Although it is well established that regular physical activity confers important health benefits and can prolong life [14, 15], there is a growing body of knowledge suggesting that repeated bouts of extreme exercise (such as UER) may have negative implications on long-term human health $[13,16]$. Long-term health problems have been defined as conditions that last at least 1 year and that require ongoing medical attention and/or limit activities of daily living [17]. However, owing to a lack of longitudinal data, the extent of long-term health issues related to UER is not decisively known. A further unknown is the extent to which pre-existing conditions may increase athlete susceptibility.

Participation of youth $(<19$ years of age $)$, masters ( $>35$ years of age), and female athletes in UER has increased exponentially over the last few years [18-22], and each group deserves special consideration owing to their greater potential for long-term health issues in this sport [23]. For example, young and physiologically less mature UER athletes may suffer more exercise-related injuries than their older and more experienced peers, and extreme bouts of exercise starting at a young age resulting in stress on an immature and developing body may lead to long-term health issues [24, 25]. Similarly, masters athletes may also be at increased risk due to pre-existing health conditions that may be exacerbated by prolonged training and racing $[26,27]$. Special consideration should also be given to the female athlete due to interactions between menstrual function and bone health [28].

This article will review the available evidence underpinning the potential long-term health problems associated with UER. To contextualize the main discussion, we first provide a short overview of the participation trends, training demands, and performance aspects, to better understand the demands and trends of UER. Thereafter, we present a synopsis of some of the most influential studies examining the possible association between UER (and endurance sports in general) and clinical health problems. This is organized by key organ systems (e.g., cardiovascular, pulmonary, musculoskeletal system) that, according to available data, are most likely to be influenced by UER, with key findings summarized in Table 1 . The authors present considerations for the prevention, monitoring, and management of these potential health problems, and offer directions for future research into the pathophysiology of UER. It is hoped that this review will inform medical best-practice in UER, as well as stimulate more open debate about the potential implications for long-term health.

\section{Methods}

The first author (VS) organized the author group in January 2021 to include recognized experts in UER from different regions of the world and with a variety of backgrounds (sports scientists and medical specialists from family medicine, sports medicine, cardiology, internal medicine, pediatrics, and orthopedics). In a series of online meetings, and via email correspondence, the authors conceived the aims and objectives of the review. Thereafter, each author drafted a section that aligned with their respective expertise and a first draft of the manuscript was subsequently developed and reviewed by all other authors. After several rounds of discussion and refining the document, each author approved the final work. All communications and discussions were performed electronically.

UER is defined as any running distance over the standard marathon $(>42.195 \mathrm{~km})$, timed events over $6 \mathrm{~h}$, or multi-day, multi-stage events [1]. Youth athletes are defined as athletes under the age of 19 years [24] and masters athletes as those over the age of 35 years [29]. Long-term health problems have been defined as conditions that last 1 year or more and/ or require ongoing medical attention or limit activities of daily living or both [17].

For the review to be comprehensive, the authors opted not to restrict studies to any given race type (e.g., singlestage vs multi-stage, road vs trail, uphill vs downhill), and while the literature search focused on responses specifically to UER (i.e., footraces), data from other ultra-endurance sports (with similar pathophysiology) were included where necessary to inform expert opinion. Articles were found primarily via three online databases (PubMed, MEDLINE, Google Scholar; with no date restrictions) with search-terms comprising the relevant body system (e.g., cardiovascular, respiratory, etc.) alongside various combinations of the following: long-term; chronic; ultra-endurance; ultra-marathon; ultramarathon; running; extreme-endurance; physiology; pathophysiology; injury; illness; disease. The reference lists of those articles included were then manually searched for additional literature. All relevant article types (metaanalyses, systematic reviews, randomized controlled trials [RCTs], exploratory studies, confirmatory studies, and case reports) were included but precedence was given to highquality research (meta-analyses and RCTs). We have also provided details in the text regarding the nature of any given study.

\section{Participation Trends}

Participation in UER has increased considerably over the last 2-3 decades, exhibiting an exponential increase that has slowed slightly since 2016 [2]. In adults, the increased participation is largely attributed to female and masters athletes $[2,18,30,31]$. The $50-\mathrm{km}$ distance is the most popular, with most finishers originating from the USA and France [2], followed by the $100-\mathrm{km}$ event wherein most finishers originate from Europe, especially France [2, 32]. Relevant 


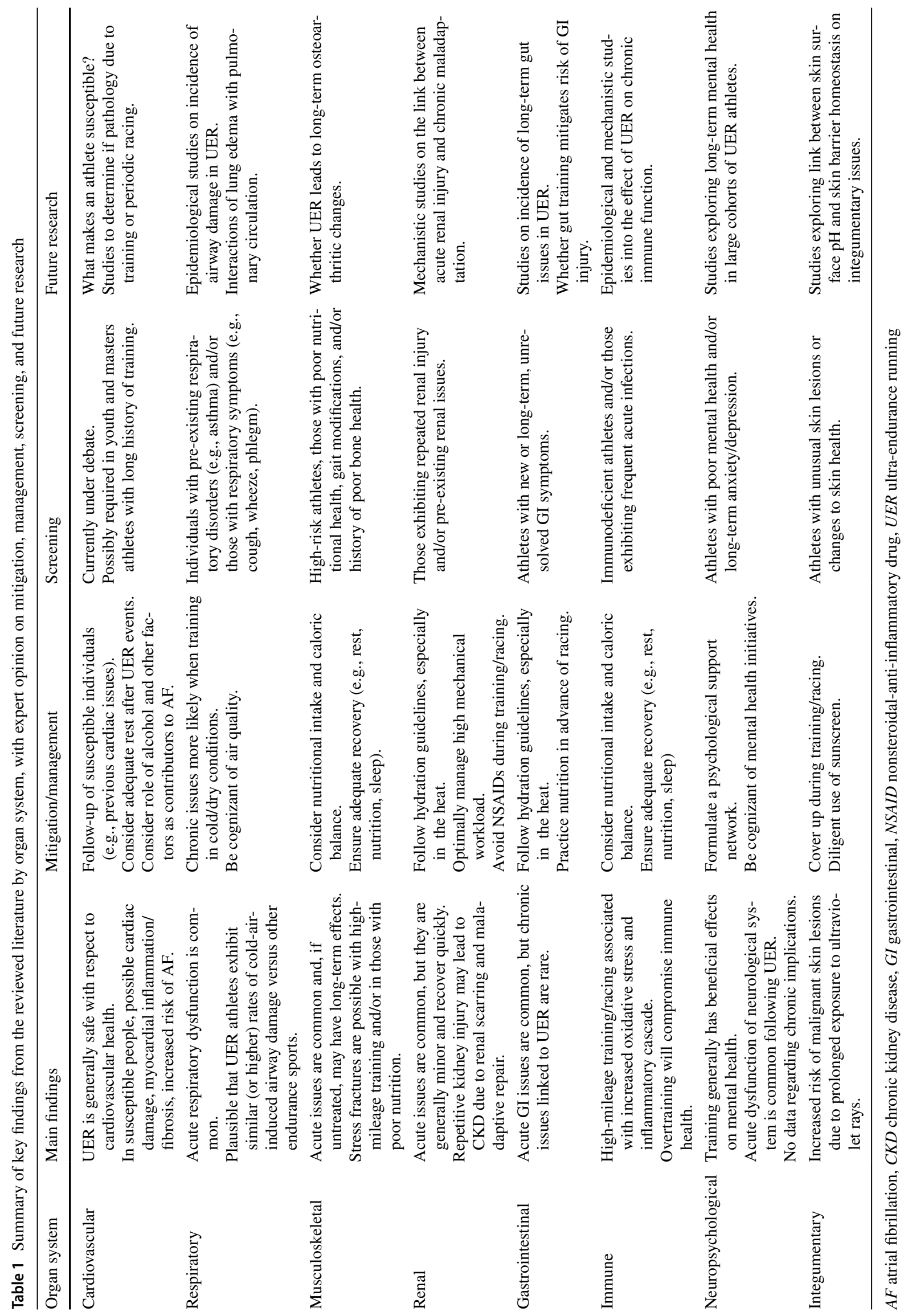


to the present review on long-term health concerns, youth participation $(<19$ years of age) in UER has also increased exponentially over the last few decades, albeit in far lower numbers when compared to adults [20-22]. The most popular running distances among youths are $50-\mathrm{km}$ and $100-$ $\mathrm{km}$ [21], with most young UER athletes between 16 and 18 years, but some were younger than 13 [21]. Collectively, these data show a considerable increase in UER participation around the world, especially in female, youth, and masters athletes.

\section{Training and Performance}

Ultra-endurance running requires high mileage training that can lead to excessive strain on the body. Average training distances in adult UER are between 66 and $83 \mathrm{~km} /$ week [9, $33,34]$ and around $57 \mathrm{~km} /$ week in youth athletes [24].

Ultra-endurance running performance is underpinned by a complex interplay among numerous physiological systems [35]. Moreover, several other variables affect UER performance such as physiological determinants, training, experience, anthropometric data, and race performance [36]. UER performance is related to average running speed in training, maximal aerobic speed [37], peak treadmill running speed [38], maximum oxygen uptake [38], average weekly running training hours [39-43], average weekly running kilometers $[34,40-42,44-46]$, and other variables such as years as an active runner [34, 42], longest training run [38, 45], number of finished marathons [39, 40, 43], ultramarathons [39-41, 43], multi-stage ultramarathons [43], pre-race records for marathon [41, 45] and specific ultramarathons [43], and personal best time in shorter races $[34,41,44,47]$ such as $5 \mathrm{~km}$ [34], $10 \mathrm{~km} \mathrm{[34],} \mathrm{half-marathon} \mathrm{[34],} \mathrm{and} \mathrm{marathon}$ [41, 41, 44, 45]. Often, for very long UER events, previous experience is more important than training [48].

Furthermore, the influence of both training (e.g., high running speed and high training volume [mean weekly running kilometers]) and anthropometric variables (e.g., body fat and muscle mass) on UER performance have been investigated [34, 40, 44-49] and seemed to be related to UER race performance [46]. Overall, training characteristics such as a high running speed and high training volume were more important than anthropometric characteristics for a successful race outcome [41, 44, 45, 48]. Multi-variate regression analyses including both anthropometric and training characteristics reduced the predictor variables mainly to body fat and speed during training units [48]. Weekly running kilometers and personal best time in $5 \mathrm{~km}, 10 \mathrm{~km}$, and half-marathon were all associated with UER performance in women [34]. For men, however, age, body mass index, years as active runner, running speed during training, and personal best time in both $5 \mathrm{~km}$ and marathon were all associated with UER performance [34].

\section{Long-Term Health Implications: Key Aspects by Organ System}

\subsection{Cardiovascular System}

Regular aerobic exercise confers various health benefits, including reduced risk of cardiovascular disease and allcause mortality $[50,51]$. Longitudinal studies specifically studying former world-class [52, 53] or leisure-time [54] athletes showed a dose-response beneficial effect in various endurance sports, including running. However, it is also established that chronic endurance exercise training has a substantial structural and functional impact on the heart, including morphological and histological cardiac remodeling, arrhythmias, sinus node dysfunction, and high coronary artery calcium (CAC) scores, although the significance and consequences of such alterations are still debated [55].

The endurance athlete's heart typically exhibits eccentric remodeling of the left ventricle (LV) and a large increase in the size of the right ventricle (RV) and atria [56-59]. Owing to a higher wall stress in the RV than in the LV during exercise [60], more than $50 \%$ of endurance athletes exhibit RV enlargement [61]. This remodeling is concomitant with the development of maximal aerobic power [62]. Potentially, some individuals with large increases in myocardial mass may also exhibit some fibrosis scars [63, 64]. Indeed, animal models of chronic endurance training show that the larger cavity size is associated with myocardial fibrosis $[65,66]$ and significant ventricular arrhythmia. There is growing evidence to confirm this histological remodeling in humans [63, 64]. A higher prevalence of LV myocardial fibrosis has been reported in apparently healthy marathoners compared to matched sedentary counterparts $[63,64]$. In fact, such alterations may be related to training experience (i.e., years of practice) [67]. Cardiac fibrosis has been described in different localizations (RV insertion point, subendocardial, subepicardial, mid-wall, or diffuse) suggesting that there is no clear relationship with endurance training, per se. In the general population, myocardial fibrosis was related to arrhythmias and mortality [68]; however, the incidence of myocardial fibrosis in UER athletes and any associated long-term consequences are yet to be comprehensively explored. The improvement in myocardial imaging (highresolution magnetic resonance imaging [MRI]) showed that fibrosis may be localized in all cavities [63]. Unlike in the LV, fibrosis in the RV or atria is clearly associated with potential adverse events. Ventricular arrhythmias, mainly originating from the RV outflow tract in endurance athletes [69], are often associated with an impaired RV function and RV fibrosis [70, 71]. 
Atrial arrhythmia, mainly atrial fibrillation (AF), can be encountered in highly trained endurance male athletes, and this abnormality may typically occur after several years of training, with a risk multiplied three- to fivefold when compared to sedentary individuals $[72,73]$. A recent meta-analysis found that younger athletes and athletes participating in mixed sports had a higher risk than those involved in endurance sports [74]. The underlying mechanisms comprise a combination of increased vagal tone, exercise dose, and anatomical and functional atrial remodeling, including atrial fibrosis [75-77]. The overall risk for exercise-related AF is, however, low; nevertheless, there is a U-shaped relationship with lifetime-accumulated high-intensity endurance training and the risk of developing AF [78, 79], and it is worth communicating this risk to UER athletes. Atrial node dysfunction [80] or exercise-induced atrio-ventricular block [81] may be further complications associated with fibrotic remodeling of the conduction system.

Another surprising finding in endurance athletes, mostly runners [82], is a high prevalence of CAC score (>100) on coronary computerized tomography (CT) angiography compared with sedentary controls $[83,84]$. The atherosclerotic plaques are, however, calcified and stable in athletes, leading to less rupture [84]. Although speculative, this may arise from long-term mechanical flexing of the epicardial coronary arteries during exercise, triggering inflammation and atherogenesis [85]. As for the LV fibrosis scars, a high CAC score might poorly predict future coronary events in athletes [86].

\subsection{Respiratory System}

The respiratory system is partially composed of conducting airways that warm, humidify, and purify inspired air before it reaches the lung parenchyma [87]. Although achieved adequately at rest, the capacity of the upper airways to condition ambient air is exceeded at minute ventilations above $35-60 \mathrm{~L} \mathrm{~min}^{-1}[87,88]$. Thus, moderateintensity exercise, as observed in UER, exposes the distal airways to unconditioned air that cools and dehydrates the epithelial surfaces [89]. The resulting inflammation can stimulate bronchial smooth muscle constriction, airway narrowing, and subsequent obstruction [90]. Such a mechanism of exercise-induced bronchoconstriction (EIB), while incompletely understood, may be important in the pathophysiology of acute lung function decline following UER [91]. Importantly, repeated acute exacerbations-particularly those involving cold/dry air-may cause injury and remodeling of the bronchial smooth muscle $[89,92]$.

EIB, which causes asthma-like symptoms in response to prolonged hyperpnea, has a prevalence of $5-20 \%$ in the general population and its prevalence is considerably higher in people with pre-existing asthma [93]. Endurance athletes are potentially at a greater risk of EIB owing to high levels of pulmonary ventilation sustained in training [94]. Although there are no epidemiological studies on the prevalence in UER, data from non-asthmatic endurance runners show that biomarkers of both airway inflammation and oxidative stress increase with exercise duration [95, 96]. The only available data relating to exercise-induced asthma in UER suggest a prevalence that is similar to that seen in the general population [97]; however, these data are limited by the self-selection of participants, the selfreporting of data, and the lack of a control group.

A further pulmonary consideration for the UER athlete relates to the potential effects of mild and transient post-race lung edemas that have been reported in marathon runners [98-100], which, in most cases, have a neurogenic pathogenesis (e.g., exercise-associated hyponatremia) [98, 101]. Competitors in a 100-mile $(161-\mathrm{km})$ footrace were shown to exhibit a mean increase in the frequency of echocardiographic "comet tails" (indicative of extravascular lung water) congruent with decreased lung diffusing capacity and alveolar-capillary membrane conductance [102]. That decreases in lung diffusing capacity occurred simultaneously with decreased RV function [103] suggests that UER confers a disproportionate hemodynamic load on the pulmonary circulation [60]. While pulmonary edema may be a normal response to strenuous endurance exercise, the short- or long-term consequences of repeated occurrences are currently unknown.

\subsection{Musculoskeletal System}

Musculoskeletal injuries are common in UER and may affect bones, joints, cartilage/menisci, muscles, tendons, ligaments, and bursae [104-107]. Around 90\% of injuries in UER are overuse in nature [104, 105, 108-110]. Most injuries are minor and affect the lower limbs, especially the foot, ankle, and knee [108, 111, 112]. Risk factors are multifactorial and include history of previous injuries, higher body mass index, advanced age, running volume, and biomechanics [105, 113, 114]. Despite the injury prevalence in UER, the long-term and cumulative effects have not been adequately studied [115]. Although recreational running in general may have positive effects on bone strength, regular high-volume running may decrease foot bone strength and increase the risk of osteopenia and/or stress fracture [116]. It has been shown that stress fractures are relatively common in UER [24, 105, $115,117]$ and may require prolonged medical treatment and absence from sporting activities. Stress fractures usually develop through overuse strain on healthy bone [118-121], with reported incidences of between 5.5 and 22\% [97, 117]. Approximately $21 \%$ of female endurance runners, including 
those contesting UER, developed stress fracture that was attributed to increased energy expenditure concomitant with inadequate nutrition [122].

Several small investigations using MRI showed no evidence of acute changes in patella-femoral and tibiofibular joint structures pre- to post-UER [123-127]. Athletes starting the race with tendinopathies demonstrated worsening MRI images after the race [123]. Tendon injuries (e.g., Achilles tendinopathy or patella tendinopathy) are relatively common in UER athletes [104, 106, 110], and although most are minor, they can become chronic and result in prolonged and recurring absences from sport [112, 128, 129].

There may be a dose-dependent association between competitive level of running and knee and hip osteoarthritis $[130,131]$. A moderate (recreational) running regimen has been shown to be associated with a lower occurrence of hip and knee osteoarthritis compared to that seen in the general population [130, 131]. However, endurance (competitive) running has been associated with a higher occurrence of hip and knee osteoarthritis compared to that seen in the general population $[130,131]$.

Other lower extremity injuries such as ligament strains, ankle sprains, iliotibial band syndrome, and plantar fasciitis, which may occur as a result of running injuries, usually have a good long-term prognosis $[104,110]$. Back pain is a common chronic condition and has been reported in 12-14\% of UER athletes [97, 117]. Nevertheless, the origin of the pain is not necessarily related to UER and may instead be the result of activities of daily life [117]. In fact, running is often seen as protective against the development of lowerback pain [132].

\subsection{Renal System}

During exercise, renal blood flow is reduced as cardiac output is redirected to the muscles, resulting in diminished renal function [133]. Severe decreases in renal function and renal failure are rare during UER [134-137]. The risk of kidney injury can be exacerbated by factors such as endurance running in extreme environments (e.g., hot and/or humid conditions, racing at altitude), severe muscle damage due to high biomechanical loads, low rates of fluid intake resulting in dehydration, the ingestion of nonsteroidal antiinflammatory drugs (NSAIDs), and genetic predisposition [134-140]. Conditions such as hyponatremia, bilirubinuria, proteinuria, hematuria, hemoglobinuria, myoglobinuria, and cylindruria can predicate acute renal issues and are indicators of acute kidney injury (AKI) in long-distance runners [133, 141-147]. These renal issues (cumulative incidence of $15-45 \%)[134,135]$ are generally minor in UER and recover to baseline values within 1-10 days [134, 145, 147-149].
Considering that AKI is usually asymptomatic, it is likely that many cases remain undetected during and after UER.

An important consideration is the extent to which AKI is associated with UER and might evoke chronic kidney damage. While individual or cumulative AKI could contribute to future chronic damage in general populations [150,151], there is no clear association in UER, and a better understanding of the physiological cascade of events is needed [140]. Any link between AKI in UER and long-term renal issues could be strengthened by certain risk factors, including age, race, genetics, and other pathological conditions.

In the general population, some evidence links acute and chronic renal failure due to potential maladaptive repair [152], and progressive renal scarring [153] due to cumulative AKI events. In this sense, there is a growing scientific literature also providing evidence that AKI accelerates the progression of chronic kidney disease (CKD) [152], that AKI repeated episodes are associated with CKD, and that the severity of AKI could lead to long-term renal issues [153]. Besides, severe cases of AKI in non-runners may require dialysis and are especially vulnerable to worse longterm renal outcomes [154]. Occasionally, AKI is detected in combination with rhabdomyolysis that may lead to a more complex condition in UER [144, 155-157]. It is currently unknown if severe renal dysfunction in UER, or repetitive renal insults that meet the criteria of AKI, lead to an accelerated progression of long-term renal issues in UER [134, $145,147,158]$.

\subsection{Gastrointestinal System}

Acute gastrointestinal (GI) issues are common during UER training and racing, with $50-80 \%$ of runners experiencing nausea, vomiting, and/or diarrhea [159-161]. Prolonged running has also been shown to evoke small intestinal damage and increased intestinal permeability [162]. However, these symptoms typically resolve with the cessation of exercise and do not appear to result in any long-term health issues; nevertheless, in extreme cases, dehydration and splanchnic hypoperfusion during exercise can lead to ischemic colitis, which in turn rarely requires surgical intervention [163]. In rare examples, chronic GI issues can lead to iron and other nutritional deficiencies [164].

In general, endurance exercise is associated with longterm benefits to the GI system, like reversal of non-alcoholic fatty liver disease and lower rates of colon cancer $[165,166]$. These findings may be in part due to beneficial effects of exercise on the gut biome $[167,168]$. Gut biome changes are typically associated with improvements in microbiota diversity, inflammatory markers, metabolic profiles, and immune responses [167-169]. 


\subsection{Immune System}

The stress produced by endurance exercise can significantly impact immune function in the short term. The immune system generally works more efficiently in athletes in whom the activity of natural killer cells is increased. Following UER, there is a transient immunosuppression for several hours, which could increase the risk of acute subclinical and clinical viral and bacterial infections. In fact, as a result of high-volume training and racing, UER athletes may be more prone to acute infections (due to reduced immunoglobulins, e.g., IgA) [170-173]. UER also results in indicators of oxidative stress (e.g., F(2)-isoprostane and lipid hydroperoxides), which increase linearly with race duration [96], in addition to increased cytokines (e.g., granulocyte colony-stimulating factor [G-CSF], interleukin [IL]-10, IL-1ra, IL-6, and IL-8), increased immune cells leading to leukocytosis, neutrophilia, and monocytosis [174], and increased cortisol, and decreased testosterone and luteinizing hormone [175].

In athletic populations, periods of overreaching may result in longer lasting immune alterations and dysfunction [176]. Importantly, physiological/psychological overload evoked from training and racing that is disproportionate to recovery may lead to non-functional overreaching, contributing to a long-term performance deficit known as under-performance syndrome [176]. Some physiological (proteomic) and perceptual (e.g., training distress score) measures could be monitored to assess non-functional overreaching in athletes, including in UER [177]. The classic physiological symptoms of overreaching include an increase in cytokines and oxidative stress as inflammation and muscle damage indicators. Consequently, it seems relatively clear that there is a link between inflammatory responses and endurance exercise, immune dysfunction, and overreaching and overtraining syndrome [178, 179]. Also, these conditions may compromise resistance to common minor illnesses, resulting in a greater incidence of infection [180].

\subsection{Neurological and Psychological Function}

Although the long-term effects of UER on the brain are unclear, MRI data collected before and after a UER event lasting 2 months (4487 km; Trans European Foot Race) showed a substantial $(6 \%)$ reduction in brain volume possibly attributable to transient loss of protein and electrolyte disturbances [181]. However, brain volume had returned to baseline at the 8-month follow-up, with no signs of permanent lesions or damage [181]. A short-term decrease in cortical activity in the frontal cortex has also been observed during 6-h UER, showing no effect on cognitive performance [182]. There are data suggesting benefits of UER on cerebral function. Indeed, a single-subject case report showed that a patient with Parkinson's disease exhibited a partial correction of abnormalities and decreased demand on medication after training for a 100-km UER event [183]. Moreover, lifelong endurance training helps maintain the cortical brain reserve [184]. As such, endurance training is most likely to have a positive impact, rather than a negative impact, on neurological health later in life.

With respect to psychological wellbeing, endurance exercise has well-documented positive effects on depression and other mental health issues [185-187]. However, UER athletes tend to exhibit significantly greater exercise dependence relative to marathon runners or athletes contesting races of shorter distances or the general population [188-190], and this could have a subsequent negative impact on health [191, 192]. The prevalence of depression and mental health issues in UER athletes is equal to or higher than that exhibited in the general population [188, 189], although this may not be causative, and it could be that people with underlying depression, anxiety, and/or other mental health issues are drawn to sports like UER, perceiving it as a way to "self-medicate."

\subsection{Integumentary System}

Dermatological problems can occur due to potential exposure to UV rays (resulting from prolonged outdoor exercise and/or high-altitude running) in addition to immunosuppression due to long-term intense exercise [193, 194]. UER athletes may be at higher risk of pre-malignant and malignant skin cancers and other UV-related health risks, e.g., adverse effects on ocular structures [193-196]. In general, athletes should be encouraged to use clothing that blocks UV radiation, use sunscreens, and wear sunglasses with UV protection to help lower the risk [193, 194, 197]. However, only $\sim 62 \%$ of UER athletes use sunscreen, a hat (52\%), or other protective clothing (7.4\%), and so clearly further education is needed [198].

\section{Special Considerations}

\subsection{Youth Athletes}

Participation of youth athletes in UER is increasing, and UER may impact growth and development in key organ systems (e.g., the cardiovascular, pulmonary, and musculoskeletal systems) during maturation in youth athletes [25]. It is currently unknown if UER is safe or poses an increased risk of acute and/or chronic injuries in youth athletes [25]. Of concern is that chronic health issues may develop earlier in susceptible individuals when participating in UER at a young age $[20,23,24]$. To date, only one retrospective observational study has described longitudinal health 
changes in 78 adults who participated in UER as youths [24]. Approximately one-quarter of youth athletes suffered from lower-limb musculoskeletal injuries (mostly knee, ankle, foot), and $6.4 \%$ developed a stress fracture [24]. As adults the overall lifetime incidence of stress fracture increased to $14 \%$ [24], which is much higher than the 5.5\% previously reported in adult UER athletes [97]. Thus, the longer physiological stress evoked by lifelong UER participation may increase the risk of injury. Only $27 \%$ of youth athletes continued running UER into adulthood, the main reason being injuries [24]. Interestingly, this study showed that most participants reported positive effects from running ultras as youth athletes, but only $\sim 21 \%$ would recommend youth athlete participation in UER [24]

To help parents, athletes, coaches, race directors, and medical professionals to reach an informed decision, a recent consensus statement [25] reviewed the evidence on health implications of youth athlete participation in UER and provided a decision-making algorithm for appropriate youth participation based on age, developmental stages, medical and psychological wellbeing, training status, and race-specific factors [25]. Until data on long-term consequences are available, youth participation in UER is not recommended on a large scale without comprehensive and individualized assessment [25].

\subsection{Masters Athletes}

A masters athlete is defined as an athlete $\geq 35$ years of age who trains for, or participates in, athletic competitions that are sometimes specifically designed for older athletes [199]. The average age to contest a first ultra-marathon is 35 years [188], and so peak performance in UER is generally achieved at an older age (i.e., between 35 and 50 years) $[31,200,201]$. Experience is a crucial component of success in UER [200], and older age seems to be an advantage regarding mitigating overuse injuries in long-distance running (i.e., younger and less experienced UER athletes are at a higher risk for exercise-related injuries such as a stress fracture) [97].

Masters UER athletes are generally a healthy population, with a lower all-type mortality and increased life expectancy compared to the general population [97, 202]. From the limited and self-reported data available, UER athletes exhibit good health, with few chronic illnesses and low use of the medical care system [97]. Whether this is due to the regular exercise or a predisposition of healthier individuals participating in UER in this relatively older age group [31, 200, 201] is not fully understood.

\subsection{Female Athletes}

There are limited data on female UER owing to reduced female participation [2, 203], possibly lesser interest in volunteering for applied research [204], and possibly because of exclusion of female subjects on the (sometimes erroneous) basis that menstrual phase might confound the physiological response [205]. Nevertheless, a recent review highlighted several key aspects of female athlete physiology that warrant careful consideration in periodized UER training plan [122].

Arguably, the most important long-term consideration for females in UER relates to interactions of energy availability and sex-hormone concentrations. The primary nutritional challenge in UER is the ability to meet daily caloric requirements [206]. A relative energy deficiency can sometimes occur due to high training volumes and/or restriction of dietary energy intake (deliberate or inadvertent); the syndrome of relative energy deficiency in sport (RED-S) refers to physiological impairments that may result [207]. Although the negative effects of low energy availability can affect both male and female athletes, its consequences are more rapid and profound in females owing to the downstream interactions with menstrual function and bone health (as described in the Female Athlete Triad [28]). A particular concern is that estrogen associates positively with bone mineral density [208]. Thus, diminished estrogen levels (e.g., in amenorrheic athletes) may increase the risk of stress fracture [209]. Even eumenorrheic females may be more susceptible than males to adverse changes in bone health following shortterm low energy availability [210]. While this likely has implications for high-mileage training, it has not yet been studied in female UER. Finally, because peak performance in UER generally occurs mid-life (e.g., at $~ 44$ years in the 24-h run [211]), female athletes should be mindful of the potential adverse changes in bone health and increased risk of osteoporosis that occur during menopause [212]. Accordingly, the data suggest there are important differences in male and female physiological function [122]. Failure to consider these differences in the design of female-specific UER training programs may have a negative impact on athlete longevity.

\subsection{Organizational Issues}

UER events often take place in remote locations and under challenging environmental conditions, with the inherent risk of severe pathologies, life-threatening injuries and occasional deaths of competitors $[6,106,213]$. Deaths have 
occurred from exercise-associated hyponatremia, cardiac issues, hyper/hypothermia, wildfires and other environmental hazards during competitions [6, 106, 213, 214], but are generally isolated occurrences that can often be prevented with appropriate pre-event medical planning [6].

\section{Future Considerations}

Moderate physical activity is well known to have positive effects on health, being preventative against numerous life-style-related diseases and reducing all-cause mortality. Similarly, many of these benefits can be derived from participation in UER, and the sport can generally be considered a safe and healthy pastime. However, it should also be recognized that with increased participation in UER comes an increased risk that susceptible individuals may experience chronic maladaptations leading to adverse effects on health and possible long-term health problems in later life (see Fig. 1). Although this review provides the current state of evidence of UER and its impact on long-term health, there remain many unknowns that warrant further exploration (see Table 1).

With regard to the cardiovascular system, UER appears generally safe; however, some susceptible UER athletes may exhibit cardiac damage, myocardial inflammation, myocardial fibrosis scars, and a higher risk of $\mathrm{AF}$ with prolonged participation. This should be explored further in UER, especially in longitudinal studies.

Similarly, long-term epidemiological studies are needed to explore the prevalence of EIB/exercise-induced asthma in ultra-marathon runners, the long-term implications of recurrent pulmonary edema associated with UER, and the implications of chronic UER-mediated RV dysfunction on the pulmonary circulation. Longitudinal studies may also provide a better understanding of kidney function through a running season and/or the lifespan, and how to prevent and treat these acute and chronic kidney conditions in a timely manner. New technological developments such as wearable devices [145, 215, 216] could allow researchers to monitor adverse changes in real-time, particularly when athletes are competing in extreme environments that are more likely to increase the incidence of AKI. Studies are also needed to explore how situational, contextual, and individual factors influence the incidence of AKI, and how this temporary loss of kidney function is related to possible long-term kidney problems [140, 145, 157]. Considering the ongoing debate regarding the use of traditional biomarkers for detection of AKI in sports, a more in-depth analysis of alternative indicators of kidney damage (e.g., neutrophil gelatinase-associated lipocalin [NGAL], kidney injury molecule [KIM]-1, cystatin $\mathrm{C}$, albumin, proenkephalin [PENK]), before and after UER events, is also warranted [156, 217, 218].

With regard to GI-related disorders, there are data suggesting that moderate-intensity exercise may be of benefit,

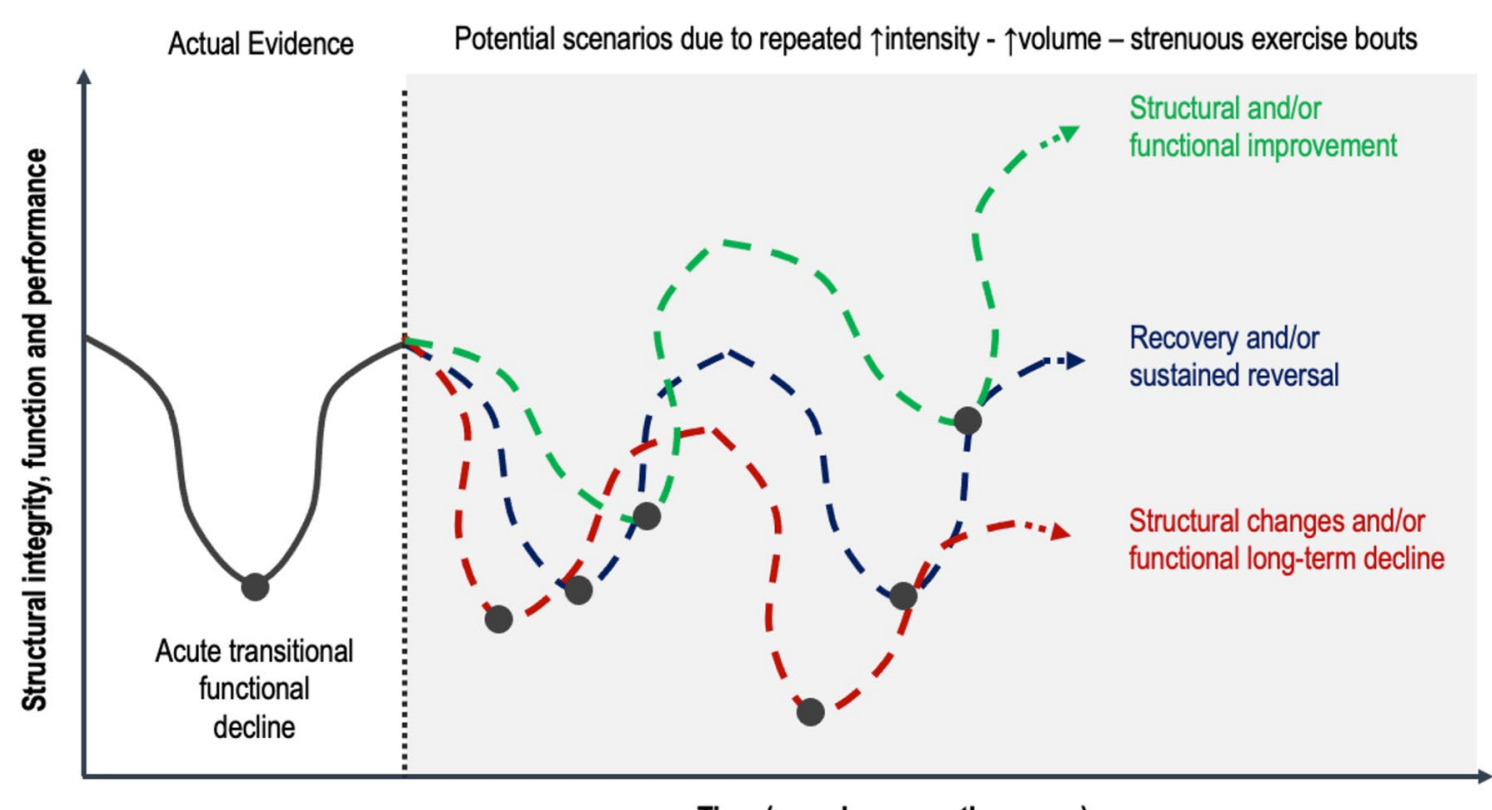

Time (e.g., days, months, years)

Fig. 1 The potential impact of repeated high-intensity/volume bouts of ultra-endurance running on key organ systems with potential maladaptations in susceptible individuals. Adapted by permission from
BMJ Publishing Group Limited, BMJ Open Sport Exerc Med, Scheer V and Rojas-Valverde D [16], Vol. 7, e001131, 2021 
but the limited data on the health effects of more strenuous exercise like UER suggest it may be detrimental. Moreover, further research is needed to establish whether acute GI disturbances associated with UER lead to chronic GI issues.

Long-term impact of UER on the musculoskeletal system should also be considered, especially with regard to stress fractures and potential osteoarthritic changes, which may occur to a greater extent in youth and female athletes.

Finally, medical screening and long-term follow-up of athletes engaging in regular UER may be an important component of risk stratification and in the early detection of long-term health concerns, but this is an ongoing point of contention. As such, careful scrutiny of the feasibility, advantages and disadvantages of screening in UER must be considered. The notion of shared decision making is relevant for UER in that clinicians and athletes should work cooperatively to consider the evidence and make an informed decision that balances the risks/expected outcomes of UER with patient preferences and values [13]. This is especially pertinent given that some of the long-term health changes may not be reversible (e.g., cardiac chamber remodeling).

\section{Conclusions}

UER is growing in popularity, particularly for youth, masters, and female athletes. There are many health benefits of participation, and UER rarely evokes serious adverse events. However, there is a growing body of evidence suggesting that UER may have implications for long-term health, particularly affecting the cardiovascular, respiratory, and musculoskeletal systems. Whether this applies only to susceptible individuals, and whether this results from high training volumes or rather the periodic stress of racing, requires further study. Future studies are needed to help better elucidate disease prevalence and pathophysiology in UER athletes.

\section{Declarations}

Funding No financial support was received for the conduct of this study, or for the preparation or publication of this article. NBT is funded by a postdoctoral fellowship from the Tobacco-Related Disease Research Program (TRDRP; award no. T31FT1692).

Conflict of interest Volker Scheer, Nicholas B. Tiller, Stéphane Doutreleau, Morteza Khodaee, Beat Knechtle, Andrew Pasternak, and Daniel Rojas-Valverde declare that they have no conflicts of interest relevant to the content of this review.

\section{Availability of data and material Not applicable.}

Authors' contributions VS and DRV conceived and designed the paper. VS organized the contributors. VS, NBT, and DRV provided the first draft, with all authors contributing to the written content, and multiple rounds of review. All authors approved the final version.

\section{References}

1. Scheer V, Basset P, Giovanelli N, Vernillo G, Millet GP, Costa RJS. Defining off-road running: a position statement from the Ultra Sports Science Foundation. Int J Sports Med. 2020;41:275-84.

2. Scheer V. Participation trends of ultra endurance events. Sports Med Arthrosc Rev. 2019;27:3-7.

3. DUV. DUV Ultra Marathon Statistics [Internet]. 2019. http:// www.ultra-marathon.org. Cited 2017 Nov 29.

4. Scheer V, Valero D, Villiger E, Rosemann T, Knechtle B. The impact of the COVID-19 pandemic on endurance and ultraendurance running. Medicina. 2021;57:52.

5. Costa RJS, Swancott AJM, Gill S, Hankey J, Scheer V, Murray A, et al. Compromised energy and macronutrient intake of ultraendurance runners during a multi-stage ultra-marathon conducted in a hot ambient environment. Int J Sports Sci. 2013;3:51-62.

6. Hoffman MD, Pasternak A, Rogers IR, Khodaee M, Hill JC, Townes DA, et al. Medical services at ultra-endurance foot races in remote environments: medical issues and consensus guidelines. Sports Med. 2014;44:1055-69.

7. Barros ES, Nascimento DC, Prestes J, Nóbrega OT, Córdova C, Sousa F, et al. Acute and chronic effects of endurance running on inflammatory markers: a systematic review. Front Physiol. 2017;18:8.

8. Giovanelli N, Taboga P, Rejc E, Lazzer S. Effects of strength, explosive and plyometric training on energy cost of running in ultra-endurance athletes. Eur J Sport Sci. 2017;17:805-13.

9. Scheer V, Vieluf S, Cramer L, Jakobsmeyer R, Heitkamp H-C. Changes in running economy during a $65-\mathrm{km}$ ultramarathon. Front Physiol. 2018;9:1809.

10. Knechtle B, Chlíbková D, Papadopoulou S, Mantzorou M, Rosemann T, Nikolaidis PT. Exercise-associated hyponatremia in endurance and ultra-endurance performance-aspects of sex, race location, ambient temperature, sports discipline, and length of performance: a narrative review. Med Kaunas Lith. 2019;55:537.

11. Paternoster N, Baggio E, Pelosi E. Personalized hydratation status in endurance and ultra-endurance: a review. Mediterr J Nutr Metab. 2020;13:197-214.

12. Rojas-Valverde D, Sánchez-Ureña B, Crowe J, Timón R, Olcina GJ. Exertional rhabdomyolysis and acute kidney injury in endurance sports: a systematic review. Eur J Sport Sci. 2020;1:0-28.

13. Tiller NB, Stewart GM, Illidi CR, Levine BD. Exercise is medicine? The cardiorespiratory implications of ultra-marathon. Curr Sports Med Rep. 2020;19:290-7.

14. Riebe D, Franklin BA, Thompson PD, Garber CE, Whitfield GP, Magal M, et al. Updating ACSM's recommendations for exercise preparticipation health screening. Med Sci Sports Exerc. 2015;47:2473-9.

15. Donnelly JE, Hillman CH, Castelli D, Etnier JL, Lee S, Tomporowski $\mathrm{P}$, et al. Physical activity, fitness, cognitive function, and academic achievement in children: a systematic review. Med Sci Sports Exerc. 2016;48:1197.

16. Scheer V, Rojas-Valverde D. Long-term health issues in ultraendurance runners: should we be concerned? BMJ Open Sport Exerc Med. 2021;7:e01131.

17. National Center for Chronic Disease Prevention and Health Promotion (NCCDPHP). About chronic diseases [Internet]. https:// www.cdc.gov/chronicdisease/about/index.htm. Cited 2020 Dec 22.

18. Zingg M, Rüst CA, Lepers R, Rosemann T, Knechtle B. Master runners dominate 24-h ultramarathons worldwide-a retrospective data analysis from 1998 to 2011. Extreme Physiol Med. 2013;2:21. 
19. Lepers R, Stapley PJ. Master athletes are extending the limits of human endurance. Front Physiol [Internet]. 2016. https://doi.org/ 10.3389/fphys.2016.00613/full. Cited 2020 Apr 21.

20. Scheer V, Hoffman MD. Too much too early? An analysis of worldwide childhood ultramarathon participation and attrition in adulthood. J Sports Med Phys Fit. 2019;59:1363-8.

21. Scheer V, Di Gangi S, Villiger E, Nikolaidis PT, Rosemann T, Knechtle B. Age-related participation and performance trends of children and adolescents in ultramarathon running. 2020;28(4):507-17.

22. Scheer V, Di Gangi S, Villiger E, Rosemann T, Nikolaidis PT, Knechtle B. Participation and performance analysis in children and adolescents competing in time-limited ultra-endurance running events. Int J Environ Res Public Health. 2020;17:1628.

23. Scheer V, Hoffman MD. Should children be running ultramarathons? Curr Sports Med Rep. 2018;17:282.

24. Scheer V, Sousa CV, Valero D, Knechtle B, Nikolaidis PT, Valero E. A descriptive study on health, training and social aspects of adults that participated in ultra endurance running as youth athletes. J Sports Med Phys Fit. 2020 (online ahead of print).

25. Scheer V, Costa R, Doutreleau S, Knechtle B, Nikolaidis PT, Roberts WO, et al. Recommendations on youth participation in ultra-endurance running events: a consensus statement. Sports Med. 2021;51(6):1123-35.

26. Knechtle B, Nikolaidis PT. Wie ungesund ist ein Ultramarathon? Praxis. 2018;107:453-62.

27. Tso J, Kim JH. Master endurance athletes and cardiovascular controversies. Curr Sports Med Rep. 2020;19:113-8.

28. Nattiv A, Loucks AB, Manore MM, Sanborn CF, Sundgot-Borgen J, Warren MP, et al. American College of Sports Medicine position stand. The female athlete triad. Med Sci Sports Exerc. 2007;39:1867-82.

29. Knechtle B, Di Gangi S, Rüst CA, Villiger E, Rosemann T, Nikolaidis PT. The role of weather conditions on running performance in the Boston Marathon from 1972 to 2018. PLoS ONE. 2019;14:e212797.

30. Eichenberger E, Knechtle B, Rüst CA, Rosemann T, Lepers R. Age and sex interactions in mountain ultramarathon running-the Swiss Alpine Marathon. Open Access J Sports Med. 2012;3:73-80.

31. Knechtle B, Rüst CA, Rosemann T, Lepers R. Age-related changes in 100-km ultra-marathon running performance. Age Dordr Neth. 2012;34:1033-45.

32. Cejka N, Rüst CA, Lepers R, Onywera V, Rosemann T, Knechtle B. Participation and performance trends in $100-\mathrm{km}$ ultra-marathons worldwide. J Sports Sci. 2014;32:354-66.

33. Kłapcińska B, Waśkiewicz Z, Chrapusta SJ, Sadowska-Krępa E, Czuba M, Langfort J. Metabolic responses to a 48-h ultramarathon run in middle-aged male amateur runners. Eur J Appl Physiol. 2013;113:2781-93.

34. O'Loughlin E, Nikolaidis PT, Rosemann T, Knechtle B. Different predictor variables for women and men in ultra-marathon running-The Wellington Urban Ultramarathon 2018. Int J Environ Res Public Health. 2019;16(10):1844.

35. Millet GY, Hoffman MD, Morin JB. Sacrificing economy to improve running performance-a reality in the ultramarathon? J Appl Physiol. 2012;113:507-9.

36. Boullosa D, Esteve-Lanao J, Casado A, Peyré-Tartaruga LA, Gomes da Rosa R, Del Coso J. Factors affecting training and physical performance in recreational endurance runners. Sports. 2020;8:35.

37. Balducci P, Clémençon M, Trama R, Blache Y, Hautier C. Performance factors in a mountain ultramarathon. Int J Sports Med. 2017;38:819-26.

38. Tan PL, Tan FH, Bosch AN. Assessment of differences in the anthropometric, physiological and training characteristics of finishers and non-finishers in a tropical 161-km ultra-marathon. Int J Exerc Sci. 2017;10:465-78.

39. Knechtle B, Wirth A, Knechtle P, Zimmermann K, Kohler G. Personal best marathon performance is associated with performance in a 24-h run and not anthropometry or training volume. Br J Sports Med. 2009;43:836-9.

40. Knechtle B, Duff B, Schulze I, Rosemann T, Senn O. Anthropometry and pre-race experience of finishers and nonfinishers in a multistage ultra-endurance run-Deutschlandlauf 2007. Percept Mot Skills. 2009;109:105-18.

41. Knechtle B, Knechtle P, Rosemann T, Lepers R. Predictor variables for a $100-\mathrm{km}$ race time in male ultra-marathoners. Percept Mot Skills. 2010;111:681-93.

42. Knechtle B, Knechtle P, Rosemann T. Race performance in male mountain ultra-marathoners: anthropometry or training? Percept Mot Skills. 2010;110:721-35.

43. Schütz UH, Ehrhardt M, Beer M, Schmidt-Trucksäss A, Billich C. Pre-race determinants influencing performance and finishing of a transcontinental 4486-km ultramarathon. J Sports Med Phys Fit. 2019;59:1608-21.

44. Knechtle B, Wirth A, Knechtle P, Rosemann T. Training volume and personal best time in marathon, not anthropometric parameters, are associated with performance in male 100-km ultrarunners. J Strength Cond Res. 2010;24:604-9.

45. Knechtle B, Knechtle P, Rosemann T, Lepers R. Personal best marathon time and longest training run, not anthropometry, predict performance in recreational 24-hour ultrarunners. J Strength Cond Res. 2011;25:2212-8.

46. Knechtle B, Knechtle P, Rosemann T, Senn O. What is associated with race performance in male $100-\mathrm{km}$ ultra-marathoners-anthropometry, training or marathon best time? J Sports Sci. 2011;29:571-7.

47. Belinchón-deMiguel P, Tornero-Aguilera JF, Dalamitros AA, Nikolaidis PT, Rosemann T, Knechtle B, et al. Multidisciplinary analysis of differences between finisher and nonfinisher ultra-endurance mountain athletes. Front Physiol. 2019;10:1507.

48. Knechtle B, Tanda G. Effects of training and anthropometric factors on marathon and $100 \mathrm{~km}$ ultramarathon race performance. Open Access J Sports Med. 2015;6:129-36.

49. Fornasiero A, Savoldelli A, Fruet D, Boccia G, Pellegrini B, Schena F. Physiological intensity profile, exercise load and performance predictors of a $65-\mathrm{km}$ mountain ultra-marathon. J Sports Sci. 2017;1-9.

50. Fiuza-Luces C, Santos-Lozano A, Joyner M, Carrera-Bastos P, Picazo O, Zugaza JL, et al. Exercise benefits in cardiovascular disease: beyond attenuation of traditional risk factors. Nat Rev Cardiol. 2018;15:731-43.

51. Lee I-M, Skerrett PJ. Physical activity and all-cause mortality: what is the dose-response relation? Med Sci Sports Exerc. 2001;33:S459-71.

52. Marijon E, Bougouin W, Périer M-C, Celermajer DS, Jouven X. Incidence of sports-related sudden death in France by specific sports and sex. JAMA. 2013;310:642-3.

53. Laukkanen JA, Kunutsor SK, Ozemek C, Mäkikallio T, Lee D-C, Wisloff U, et al. Cross-country skiing and running's association with cardiovascular events and all-cause mortality: a review of the evidence. Prog Cardiovasc Dis. 2019;62:505-14.

54. Laukkanen JA, Laukkanen T, Kunutsor SK. Cross-country skiing is associated with lower all-cause mortality: a population-based follow-up study. Scand J Med Sci Sports. 2018;28:1064-72.

55. Parry-Williams G, Sharma S. The effects of endurance exercise on the heart: panacea or poison? Nat Rev Cardiol. 2020;17:402-12. 
56. D'Andrea A, Riegler L, Cocchia R, Scarafile R, Salerno G, Gravino R, et al. Left atrial volume index in highly trained athletes. Am Heart J. 2010;159:1155-61.

57. D'Andrea A, La Gerche A, Golia E, Padalino R, Calabrò R, Russo MG, et al. Physiologic and pathophysiologic changes in the right heart in highly trained athletes. Herz. 2015;40:369-78.

58. Heidbüchel H. High prevalence of right ventricular involvementin endurance athletes with ventricular arrhythmias Role of an electrophysiologic study in risk stratification. Eur Heart J. 2003;24:1473-80.

59. La Gerche A, Connelly KA, Mooney DJ, MacIsaac AI, Prior DL. Biochemical and functional abnormalities of left and right ventricular function after ultra-endurance exercise. Heart. 2008;94:860-6.

60. La Gerche A, Heidbüchel H, Burns AT, Mooney DJ, Taylor AJ, Pfluger HB, et al. Disproportionate exercise load and remodeling of the athlete's right ventricle. Med Sci Sports Exerc. 2011;43:974-81.

61. Zaidi A, Ghani S, Sharma R, Oxborough D, Panoulas VF, Sheikh N, et al. Physiological right ventricular adaptation in elite athletes of African and Afro-Caribbean origin. Circulation. 2013;127:1783-92.

62. La Gerche A, Burns AT, Taylor AJ, Macisaac AI, Heidbüchel $\mathrm{H}$, Prior DL. Maximal oxygen consumption is best predicted by measures of cardiac size rather than function in healthy adults. Eur J Appl Physiol. 2012;112:2139-47.

63. Wilson M, O'Hanlon R, Prasad S, Deighan A, Macmillan P, Oxborough D, et al. Diverse patterns of myocardial fibrosis in lifelong, veteran endurance athletes. J Appl Physiol Bethesda MD. 1985;2011(110):1622-6.

64. van de Schoor FR, Aengevaeren VL, Hopman MTE, Oxborough DL, George KP, Thompson PD, et al. Myocardial fibrosis in athletes. Mayo Clin Proc. 2016;91:1617-31.

65. Benito B, Gay-Jordi G, Serrano-Mollar A, Guasch E, Shi Y, Tardif J-C, et al. Cardiac arrhythmogenic remodeling in a rat model of long-term intensive exercise training. Circulation. 2011;123:13-22.

66. Rao Z, Wang S, Bunner WP, Chang Y, Shi R. Exercise induced right ventricular fibrosis is associated with myocardial damage and inflammation. Korean Circ J. 2018;48:1014-24.

67. Tahir E, Starekova J, Muellerleile K, von Stritzky A, Münch J, Avanesov M, et al. Myocardial fibrosis in competitive triathletes detected by contrast-enhanced CMR correlates with exerciseinduced hypertension and competition history. JACC Cardiovasc Imaging. 2018;11:1260-70.

68. Kwong RY, Chan AK, Brown KA, Chan CW, Reynolds HG, Tsang S, et al. Impact of unrecognized myocardial scar detected by cardiac magnetic resonance imaging on event-free survival in patients presenting with signs or symptoms of coronary artery disease. Circulation. 2006;113:2733-43.

69. Zorzi A, Mastella G, Cipriani A, Berton G, Del Monte A, Gusella $\mathrm{B}$, et al. Burden of ventricular arrhythmias at 12-lead 24-hour ambulatory ECG monitoring in middle-aged endurance athletes versus sedentary controls. Eur J Prev Cardiol. 2018;25:2003-11.

70. Zaidi A, Sharma S. Arrhythmogenic right ventricular remodelling in endurance athletes: Pandora's box or Achilles' heel? Eur Heart J. 2015;36:1955-7.

71. Lie $\varnothing \mathrm{H}$, Klaboe LG, Dejgaard LA, Skjølsvik ET, Grimsmo $\mathrm{J}$, Bosse $\mathrm{G}$, et al. Cardiac phenotypes and markers of adverse outcome in elite athletes with ventricular arrhythmias. JACC Cardiovasc Imaging. 2021;14:148-58.

72. Mont L, Elosua R, Brugada J. Endurance sport practice as a risk factor for atrial fibrillation and atrial flutter. Eur Eur Pacing Arrhythm Card Electrophysiol J Work Groups Card
Pacing Arrhythm Card Cell Electrophysiol Eur Soc Cardiol. 2009;11:11-7.

73. Cervellin G, Sanchis-Gomar F, Filice I, Lippi G. Paroxysmal atrial fibrillation in young and middle-aged athletes (PAFIYAMA) syndrome in the real world: a paradigmatic case report. Cardiovasc Diagn Ther. 2018;8:176-9.

74. Newman W, Parry-Williams G, Wiles J, Edwards J, Hulbert S, Kipourou K, et al. Risk of atrial fibrillation in athletes: a systematic review and meta-analysis. Br J Sports Med. 2021;bjsports-2021-103994.

75. Mont L, Tamborero D, Elosua R, Molina I, Coll-Vinent B, Sitges M, et al. Physical activity, height, and left atrial size are independent risk factors for lone atrial fibrillation in middleaged healthy individuals. Eur Eur Pacing Arrhythm Card Electrophysiol J Work Groups Card Pacing Arrhythm Card Cell Electrophysiol Eur Soc Cardiol. 2008;10:15-20.

76. Peritz DC, Catino AB, Csecs I, Kaur G, Kheirkhahan M, Loveless B, et al. High-intensity endurance training is associated with left atrial fibrosis. Am Heart J. 2020;226:206-13.

77. Trivedi SJ, Claessen G, Stefani L, Flannery MD, Brown P, Janssens K, et al. Differing mechanisms of atrial fibrillation in athletes and non-athletes: alterations in atrial structure and function. Eur Heart J Cardiovasc Imaging. 2020;21:1374-83.

78. Garnvik LE, Malmo V, Janszky I, Wisløff U, Loennechen JP, Nes BM. Estimated cardiorespiratory fitness and risk of atrial fibrillation: the Nord-Trøndelag Health Study. Med Sci Sports Exerc. 2019;51:2491-7.

79. Drca N, Wolk A, Jensen-Urstad M, Larsson SC. Atrial fibrillation is associated with different levels of physical activity levels at different ages in men. Heart Br Card Soc. 2014;100:1037-42.

80. Stein R, Medeiros CM, Rosito GA, Zimerman LI, Ribeiro JP. Intrinsic sinus and atrioventricular node electrophysiologic adaptations in endurance athletes. J Am Coll Cardiol. 2002;39:1033-8.

81. Doutreleau S, Pistea C, Lonsdorfer E, Charloux A. Exerciseinduced second-degree atrioventricular block in endurance athletes. Med Sci Sports Exerc. 2013;45:411-4.

82. Aengevaeren VL, Mosterd A, Sharma S, Braber TL, Thompson PD, Velthuis BK, et al. Coronary atherosclerosis in athletes: exploring the role of sporting discipline. JACC Cardiovasc Imaging. 2019;12:1587-9.

83. Aengevaeren VL, Mosterd A, Braber TL, Prakken NHJ, Doevendans PA, Grobbee DE, et al. Relationship between lifelong exercise volume and coronary atherosclerosis in athletes. Circulation. 2017;136:138-48.

84. Merghani A, Maestrini V, Rosmini S, Cox AT, Dhutia H, Bastiaenan R, et al. Prevalence of subclinical coronary artery disease in masters endurance athletes with a low atherosclerotic risk profile. Circulation. 2017;136:126-37.

85. Franck G, Even G, Gautier A, Salinas M, Loste A, Procopio E, et al. Haemodynamic stress-induced breaches of the arterial intima trigger inflammation and drive atherogenesis. Eur Heart J. 2019;40:928-37.

86. DeFina LF, Radford NB, Barlow CE, Willis BL, Leonard D, Haskell WL, et al. Association of all-cause and cardiovascular mortality with high levels of physical activity and concurrent coronary artery calcification. JAMA Cardiol. 2019;4:174-81.

87. Daviskas E, Gonda I, Anderson SD. Local airway heat and water vapour losses. Respir Physiol. 1991;84:115-32.

88. Niinimaa V, Cole P, Mintz S, Shephard RJ. The switching point from nasal to oronasal breathing. Respir Physiol. 1980;42:61-71.

89. Kippelen P, Anderson SD. Airway injury during high-level exercise. Br J Sports Med. 2012;46:385-90. 
90. Gotshall RW. Exercise-induced bronchoconstriction. Drugs. 2002;62:1725-39.

91. Tiller NB. Pulmonary and respiratory muscle function in response to marathon and ultra-marathon running: a review. Sports Med. 2019;49:1031-41.

92. Carlsen K-H. Sports in extreme conditions: the impact of exercise in cold temperatures on asthma and bronchial hyper-responsiveness in athletes. Br J Sports Med. 2012;46:796-9.

93. Aggarwal B, Mulgirigama A, Berend N. Exercise-induced bronchoconstriction: prevalence, pathophysiology, patient impact, diagnosis and management. NPJ Prim Care Respir Med. 2018;28:31.

94. Boulet L-P, O’Byrne PM. Asthma and exercise-induced bronchoconstriction in athletes. N Engl J Med. 2015;372:641-8.

95. Araneda O, Guevara A, Contreras C, Lagos N, Berral F. Exhaled breath condensate analysis after long distance races. Int J Sports Med. 2012;33:955-61.

96. Vezzoli A, Dellanoce C, Mrakic-Sposta S, Montorsi M, Moretti $\mathrm{S}$, Tonini A, et al. Oxidative stress assessment in response to ultraendurance exercise: Thiols Redox Status and ROS Production according to duration of a competitive race. Oxid Med Cell Longev. 2016;2016:1-13.

97. Hoffman MD, Krishnan E. Health and exercise-related medical issues among 1,212 ultramarathon runners: baseline findings from the Ultrarunners Longitudinal TRAcking (ULTRA) Study. PLoS ONE. 2014;9:e83867.

98. Young M, Sciurba F, Rinaldo J. Delirium and pulmonary edema after completing a marathon. Am Rev Respir Dis. 1987;136:737-9.

99. Zavorsky GS, Milne ENC, Lavorini F, Rienzi JP, Cutrufello PT, Kumar SS, et al. Small changes in lung function in runners with marathon-induced interstitial lung edema. Physiol Rep. 2014;2:e12056

100. Aoun J, Dgayli K, Abou Zeid C, Wong G, LaCamera P. Pulmonary edema during the Boston Marathon. Respir Med Case Rep. 2019;27:100845.

101. Sanchez LD, Corwell B, Berkoff D. Medical problems of marathon runners. Am J Emerg Med. 2006;24:608-15.

102. Stewart G, Jorgenson C, Wheatley C, Robach P, Gavet A, Ziegler B, et al. Effect of ultra-endurance exercise on alveolar-capillary recruitment and lung diffusion: 68 board \#8 May 29 9:30 AM-11:30 AM. Med Sci Sports Exerc. 2019;51:5.

103. Stewart G, Fermoyle C, Wheatley C, Ziegler B, Johnson B. Influence of ultra-endurance exercise on alveolar-capillary recruitment and lung diffusion. Clin Respir Physiol Exerc Funct Imaging [Internet]. 2018. https://doi.org/10.1183/13993003.congr ess-2018.PA2441

104. Khodaee M, Ansari M. Common ultramarathon injuries and illnesses: race day management. Curr Sports Med Rep. 2012;11:290-7.

105. Krabak BJ, Waite B, Lipman G. Evaluation and treatment of injury and illness in the ultramarathon athlete. Phys Med Rehabil Clin N Am. 2014;25:845-63.

106. Scheer BV, Murray DA. Ultramarathon Running Injuries. In: Doral MN, Karlsson J, editors. Sports Inj [Internet]. Springer Berlin; 2015. pp. 2889-98. https://doi.org/10.1007/978-3-64236569-0_216. Cited 22 Oct 2017.

107. Scheer V, Krabak B. Musculoskeletal injuries in ultra-endurance running: a scoping review. Front. Physiol. 2021;12:664071 https://doi.org/10.3389/fphys.2021.664071.

108. Krabak BJ, Waite B, Schiff MA. Study of injury and illness rates in multiday ultramarathon runners. Med Sci Sports Exerc. 2011;43:2314-20.

109. Scheer BV, Murray A. Al Andalus Ultra Trail: an observation of medical interventions during a 219-km, 5-day ultramarathon stage race. Clin J Sport Med Off J Can Acad Sport Med. 2011;21:444-6.

110. Lopes AD, Hespanhol LC, Yeung SS, Costa LOP. What are the main running-related musculoskeletal injuries? A systematic review. Sports Med. 2012;42:891-905.

111. Fallon KE. Musculoskeletal injuries in the ultramarathon: the 1990 Westfield Sydney to Melbourne run. Br J Sports Med. 1996;30:319-23.

112. Bishop GW, Fallon KE. Musculoskeletal injuries in a sixday track race: ultramarathonerlM' s ankle. Clin J Sport Med. 1999;9:216-20.

113. van Poppel D, van der Worp M, Slabbekoorn A, van den Heuvel SSP, van Middelkoop M, Koes BW, et al. Risk factors for overuse injuries in short- and long-distance running: a systematic review. J Sport Health Sci. 2020;10:14-28.

114. Xu Y, Yuan P, Wang R, Wang D, Liu J, Zhou H. Effects of foot strike techniques on running biomechanics: a systematic review and meta-analysis. Sports Health. 2021;13:71-7.

115. Micklesfield LK, Hugo J, Johnson C, Noakes TD, Lambert EV. Factors associated with menstrual dysfunction and self-reported bone stress injuries in female runners in the ultra- and half-marathons of the Two Oceans. Br J Sports Med. 2007;41:679-83.

116. Garofolini A, Taylor S. The effect of running on foot muscles and bones: a systematic review. Hum Mov Sci. 2019;64:75-88.

117. Malliaropoulos N, Mertyri D, Tsaklis P. Prevalence of injury in ultra trail running. Hum Mov. 2015;16:52-9.

118. Harrast MA, Colonno D. Stress fractures in runners. Clin Sports Med. 2010;29:399-416.

119. Pegrum J, Crisp T, Padhiar N. Diagnosis and management of bone stress injuries of the lower limb in athletes. BMJ. 2012;344:e2511.

120. Krabak BJ, Tenforde AS, Davis IS, Fredericson M, Harrast MA, d'Hemecourt P, et al. Youth distance running: strategies for training and injury reduction. Curr Sports Med Rep. 2019;18:53-9.

121. Tenforde AS, Roberts WO, Krabak BJ, Davis IS, Fredericson M, Luke AC, et al. Recommendations to optimize health in youth runners. Strength Cond J. 2019;1:76-82.

122. Tiller NB, Elliott-Sale KJ, Knechtle B, Wilson PB, Roberts JD, Millet GY. Do sex differences in physiology confer a female advantage in ultra-endurance sport? Sports Med [Internet]. 2021. https://doi.org/10.1007/s40279-020-01417-2. Cited 1 Feb 2021.

123. Hagemann GJ, Rijke AM, Corr PD. Do knees survive the Comrades Marathon? South Afr Med J. 2008;98:873-6.

124. Schütz UHW, Ellermann J, Schoss D, Wiedelbach H, Beer M, Billich C. Biochemical cartilage alteration and unexpected signal recovery in $\mathrm{T} 2 *$ mapping observed in ankle joints with mobile MRI during a transcontinental multistage footrace over $4486 \mathrm{~km}$. Osteoarthritis Cartil. 2014;22:1840-50.

125. Schütz U, Billich C, Schoss D, Beer M, Ellermann J. MRI cartilage assessment of the subtalar and midtarsal joints during a transcontinental ultramarathon-new insights into human locomotion. Int J Sports Med. 2018;39:37-49.

126. Schütz UH-W, Brix M, Kiess A, Goed S, Friedrich K, Weber $\mathrm{M}$, et al. Femoropatellar joint reaction detected during a $4486 \mathrm{KM}$ ultramarathon with mobile MRI. Int J Sports Med. 2020;41:398-411.

127. Diermeier T, Beitzel K, Bachmann L, Petersen W, Esefeld K, Wörtler K, et al. Mountain ultramarathon results in temporary meniscus extrusion in healthy athletes. Knee Surg Sports Traumatol Arthrosc. 2019;27:2691-7.

128. Hutson MA. Medical implications of ultra marathon running: observations on a six day track race. Br J Sports Med. 1984;18:44-5.

129. Maffulli N, Longo UG, Kadakia A, Spiezia F. Achilles tendinopathy. Foot Ankle Surg. 2020;26:240-9. 
130. Alentorn-Geli E, Samuelsson K, Musahl V, Green CL, Bhandari M, Karlsson J. The association of recreational and competitive running with hip and knee osteoarthritis: a systematic review and meta-analysis. J Orthop Sports Phys Ther. 2017;47:373-90.

131. Gessel T, Harrast MA. Running dose and risk of developing lower-extremity osteoarthritis. Curr Sports Med Rep. 2019;18:201-9.

132. Maselli F, Storari L, Barbari V, Colombi A, Turolla A, Gianola S, et al. Prevalence and incidence of low back pain among runners: a systematic review. BMC Musculoskelet Disord. 2020;21:343.

133. Gerth J, Ott U, Fünfstück R, Bartsch R, Keil E, Schubert K, et al. The effects of prolonged physical exercise on renal function, electrolyte balance and muscle cell breakdown. Clin Nephrol. 2002; $57: 425-31$.

134. Kao W-F, Hou S-K, Chiu Y-H, Chou S-L, Kuo F-C, Wang S-H, et al. Effects of 100-km ultramarathon on acute kidney injury. Clin J Sport Med. 2015;25:49-54.

135. Lipman GS, Shea K, Christensen M, Phillips C, Burns P, Higbee $\mathrm{R}$, et al. Ibuprofen versus placebo effect on acute kidney injury in ultramarathons: a randomised controlled trial. Emerg Med J. 2017;34:637-42.

136. de Souza RF, de Matos DG, Ferreira ARP, Chilibeck P, Barros NA, Oliveira AS, et al. Effect of ibuprofen on muscle, hematological and renal function, hydric balance, pain, and performance during intense long-distance running. J Strength Cond Res. 2020;34:2076-83.

137. Scheer V. Severe kidney injury after a $110-\mathrm{km}$ trail race. Cureus. 2020;12:e7814.

138. Page AJ, Reid SA, Speedy DB, Mulligan GP, Thompson J. Exercise-associated hyponatremia, renal function, and nonsteroidal antiinflammatory drug use in an ultraendurance mountain run. Clin J Sport Med. 2007;17:43-8.

139. Eichner ER. Is heat stress nephropathy a concern for endurance athletes? Curr Sports Med Rep. 2017;16:299-300.

140. Rojas-Valverde D, Olcina G, Gutiérrez-Vargas R, Crowe J. Heat strain, external workload, and chronic kidney disease in tropical settings: are endurance athletes exposed? Front Physiol. 2019;10:1403.

141. Bruso JR, Hoffman MD, Rogers IR, Lee L, Towle G, Hew-Butler T. Rhabdomyolysis and hyponatremia: a cluster of five cases at the 161-km 2009 Western States Endurance Run. Wilderness Environ Med. 2010;21:303-8.

142. Boulter J, Noakes TD, Hew-Butler T. Acute renal failure in four Comrades Marathon runners ingesting the same electrolyte supplement: coincidence or causation? South Afr Med J. 2011;101:876-8.

143. Belli T, Macedo DV, de Araújo GG, Dos Reis IGM, Scariot PPM, Lazarim FL, et al. Mountain Ultramarathon induces early increases of muscle damage, inflammation, and risk for acute renal injury. Front Physiol. 2018;9:1368.

144. Wołyniec W, Ratkowski W, Kasprowicz K, Jastrzębski Z, Małgorzewicz S, Witek K, et al. Glomerular filtration rate is unchanged by ultramarathon. J Strength Cond Res. 2018;32:3207-15.

145. Rojas-Valverde D, Sánchez-Ureña B, Crowe J, Timón R, Olcina GJ. Exertional rhabdomyolysis and acute kidney injury in endurance sports: a systematic review. Eur J Sport Sci. 2021;21:261-74.

146. Khodaee M, Saeedi A, Irion B, Spittler J, Hoffman MD. Proteinuria in a high-altitude $161-\mathrm{km}$ (100-mile) ultramarathon. Phys Sportsmed. 2021;49:92-9.

147. Hoffman MD, Weiss RH. Does acute kidney injury from an ultramarathon increase the risk for greater subsequent injury? Clin J Sport Med. 2016;26:417-22.
148. Lipman GS, Krabak BJ, Waite BL, Logan SB, Menon A, Chan GK. A prospective cohort study of acute kidney injury in multistage ultramarathon runners: the Biochemistry in Endurance Runner Study (BIERS). Res Sports Med. 2014;22:185-92.

149. Lipman GS, Krabak BJ, Rundell SD, Shea KM, Badowski $\mathrm{N}$, Little $\mathrm{C}$. Incidence and prevalence of acute kidney injury during multistage ultramarathons. Clin J Sport Med. 2016;26:314-9.

150. Coca SG, Singanamala S, Parikh CR. Chronic kidney disease after acute kidney injury: a systematic review and meta-analysis. Kidney Int. 2012;81:442-8.

151. Palant CE, Amdur RL, Chawla LS. The acute kidney injury to chronic kidney disease transition: a potential opportunity to improve care in acute kidney injury. Contrib Nephrol. 2016;187:55-72.

152. Chawla LS, Eggers PW, Star RA, Kimmel PL. Acute kidney injury and chronic kidney disease as interconnected syndromes. N Engl J Med. 2014;371:58-66.

153. Ferenbach DA, Bonventre JV. Acute kidney injury and chronic kidney disease: from the laboratory to the clinic. Néphrologie Thérapeutique. 2016;12:S41-8.

154. Hsu RK, Hsu C-Y. The role of acute kidney injury in chronic kidney disease. Semin Nephrol. 2016;36:283-92.

155. Poussel M, Touzé C, Allado E, Frimat L, Hily O, Thilly N, et al. Ultramarathon and renal function: does exercise-induced acute kidney injury really exist in common conditions? Front Sports Act Living. 2020;1:71.

156. McCullough PA, Shaw AD, Haase M, Bouchard J, Waikar SS, Siew ED, et al. Diagnosis of acute kidney injury using functional and injury biomarkers: workgroup statements from the tenth acute dialysis quality initiative consensus conference. In: McCullough PA, Kellum JA, Mehta RL, Murray PT, Ronco C, editors. Contrib Nephrol [Internet]. Basel: S. KARGER AG; 2013. pp. 13-29. https://www.karger.com/Article/FullText/ 349963. Cited 2021 Feb 1.

157. Rojas-Valverde D, Olcina G, Sánchez-Ureña B, Pino-Ortega J, Martínez-Guardado I, Timón R. Proteinuria and bilirubinuria as potential risk indicators of acute kidney injury during running in outpatient settings. Medicina (Mex). 2020;56:562.

158. Hodgson L, Walter E, Venn R, Galloway R, Pitsiladis Y, Sardat $\mathrm{F}$, et al. Acute kidney injury associated with endurance events-is it a cause for concern? A systematic review. BMJ Open Sport Exerc Med. 2017;3:e000093.

159. Hoffman MD, Fogard K. Factors related to successful completion of a 161-km ultramarathon. Int J Sports Physiol Perform. 2011;6:25-37.

160. Stuempfle KJ, Hoffman MD. Gastrointestinal distress is common during a $161-\mathrm{km}$ ultramarathon. J Sports Sci. 2015;33:1814-21.

161. Wardenaar FC, Dijkhuizen R, Ceelen IJM, Jonk E, De Vries JHM, Witkamp RF, et al. Nutrient intake by ultramarathon runners: can they meet recommendations? Int J Sport Nutr Exerc Metab. 2015;25:375-86.

162. Karhu E, Forsgård RA, Alanko L, Alfthan H, Pussinen P, Hämäläinen E, et al. Exercise and gastrointestinal symptoms: running-induced changes in intestinal permeability and markers of gastrointestinal function in asymptomatic and symptomatic runners. Eur J Appl Physiol. 2017;117:2519-26.

163. Moses FM. Exercise-associated intestinal ischemia. Curr Sports Med Rep. 2005;4:91-5.

164. Coates A, Mountjoy M, Burr J. Incidence of iron deficiency and iron deficient anemia in elite runners and triathletes. Clin J Sport Med. 2017;27:493-8.

165. Martin D. Physical activity benefits and risks on the gastrointestinal system. South Med J. 2011;104:831-7. 
166. Rinella ME, Sanyal AJ. Management of NAFLD: a stage-based approach. Nat Rev Gastroenterol Hepatol. 2016;13:196-205.

167. Donati Zeppa S, Agostini D, Gervasi M, Annibalini G, Amatori $\mathrm{S}$, Ferrini F, et al. Mutual interactions among exercise, sport supplements and microbiota. Nutrients. 2019;12:17.

168. Sohail MU, Yassine HM, Sohail A, Al Thani AA. Impact of physical exercise on gut microbiome, inflammation, and the pathobiology of metabolic disorders. Rev Diabet Stud. 2019;15:35-48.

169. Grosicki GJ, Durk RP, Bagley JR. Rapid gut microbiome changes in a world-class ultramarathon runner. Physiol Rep. 2019;7:e14313.

170. Nieman DC, Dumke CL, Henson DA, McAnulty SR, Gross SJ, Lind RH. Muscle damage is linked to cytokine changes following a 160-km race. Brain Behav Immun. 2005;19:398-403.

171. Nieman DC, Henson DA, Dumke CL, Oley K, McAnulty SR, Davis JM, et al. Ibuprofen use, endotoxemia, inflammation, and plasma cytokines during ultramarathon competition. Brain Behav Immun. 2006;20:578-84.

172. Pacque PFJ, Booth CK, Ball MJ, Dwyer DB. The effect of an ultra-endurance running race on mucosal and humoral immune function. J Sports Med Phys Fit. 2007;47:496-501.

173. Gill S, Teixeira A, Rosado F, Hankey J, Wright A, Marczak S, et al. The impact of a 24-h ultra-marathon on salivary antimicrobial protein responses. Int J Sports Med. 2014;35:966-71.

174. Shin YO, Lee JB. Leukocyte chemotactic cytokine and leukocyte subset responses during ultra-marathon running. Cytokine. 2013;61:364-9.

175. Kupchak BR, Kraemer WJ, Hoffman MD, Phinney SD, Volek JS. The Impact of an ultramarathon on hormonal and biochemical parameters in men. Wilderness Environ Med. 2014;25:278-88.

176. Budgett R. Redefining the overtraining syndrome as the unexplained underperformance syndrome. Br J Sports Med. 2000;34:67-8.

177. Saw AE, Main LC, Gastin PB. Monitoring the athlete training response: subjective self-reported measures trump commonly used objective measures: a systematic review. Br J Sports Med. 2016;50:281-91.

178. Gleeson M. Immune function in sport and exercise. J Appl Physiol. 2007;103:693-9.

179. Nieman DC. Marathon training and immune function. Sports Med. 2007;37:412-5.

180. Gleeson M. Immune system adaptation in elite athletes. Curr Opin Clin Nutr Metab Care. 2006;9:659-65.

181. Freund W, Faust S, Birklein F, Gaser C, Wunderlich AP, Müller M, et al. Substantial and reversible brain gray matter reduction but no acute brain lesions in ultramarathon runners: experience from the TransEurope-FootRace Project. BMC Med. 2012;10:170.

182. Wollseiffen P, Schneider S, Martin LA, Kerhervé HA, Klein T, Solomon C. The effect of $6 \mathrm{~h}$ of running on brain activity, mood, and cognitive performance. Exp Brain Res. 2016;234:1829-36.

183. Daviet JC, Roy X, Quelven-Bertin I, Jallageas R, Mandigout S, Torny F, et al. Parkinson's patient runs an ultra marathon: a case report. Eur J Phys Rehabil Med. 2014;50:447-51.

184. Wood KN, Nikolov R, Shoemaker JK. Impact of long-term endurance training vs. guideline-based physical activity on brain structure in healthy aging. Front Aging Neurosci. 2016;8:155.

185. Krogh J, Speyer H, Gluud C, Nordentoft M. Exercise for patients with major depression: a protocol for a systematic review with meta-analysis and trial sequential analysis. Syst Rev. 2015;4:40.

186. Kvam S, Kleppe CL, Nordhus IH, Hovland A. Exercise as a treatment for depression: a meta-analysis. J Affect Disord. 2016;202:67-86.

187. Béland M, Lavoie KL, Briand S, White UJ, Gemme C, Bacon SL. Aerobic exercise alleviates depressive symptoms in patients with a major non-communicable chronic disease: a systematic review and meta-analysis. Br J Sports Med. 2020;54:272-8.

188. Hoffman MD, Krishnan E. Exercise behavior of ultramarathon runners: baseline findings from the ULTRA study. J Strength Cond Res. 2013;27:2939-45.

189. Onate J. Depression in ultra-endurance athletes, a review and recommendations. Sports Med Arthrosc Rev. 2019;27:31-4.

190. Pierce EF, McGowan RW, Lynn TD. Exercise dependence in relation to competitive orientation of runners. J Sports Med Phys Fit. 1993;33:189-93.

191. Buck K, Spittler J, Reed A, Khodaee M. Psychological attributes of ultramarathoners. Wilderness Environ Med. 2018;29:66-71.

192. Hoffman MD, Krouse R. Ultra-obligatory running among ultramarathon runners. Res Sports Med. 2018;26:211-21.

193. Ambros-Rudolph CM, Hofmann-Wellenhof R, Richtig E, MüllerFürstner M, Soyer HP, Kerl H. Malignant melanoma in marathon runners. Arch Dermatol. 2006;142:1471-4.

194. Moehrle M. Outdoor sports and skin cancer. Clin Dermatol. 2008;26:12-5.

195. Purim KSM, Leite N. Sports-related dermatoses among road runners in Southern Brazil. An Bras Dermatol. 2014;89:587-92.

196. Snyder A, Valdebran M, Terrero D, Amber KT, Kelly KM. Solar ultraviolet exposure in individuals who perform outdoor sport activities. Sports Med Open. 2020;6:42.

197. Khodaee M, Grothe HL, Seyfert JH, VanBaak K. Athletes at high altitude. Sports Health Multidiscip Approach. 2016;8:126-32.

198. García-Malinis AJ, Gracia-Cazaña T, Zazo M, Aguilera J, Rivas-Ruiz F, de Troya MM, et al. Hábitos y conocimientos sobre fotoprotección y factores de riesgo para quemadura solar en corredores de maratones de montaña. Actas Dermosifiliogr. 2021;112:159-66.

199. Trappe S. Master athletes. Int J Sport Nutr Exerc Metab. 2001;11:S196-207.

200. Hoffman MD, Parise CA. Longitudinal assessment of the effect of age and experience on performance in 161-km ultramarathons. Int J Sports Physiol Perform. 2015;10:93-8.

201. Nikolaidis PT, Knechtle B. Performance in 100-km ultramarathoners-at which age, it reaches its peak? J Strength Cond Res. 2020;34:1409-15.

202. Hoffman MD, Fogard K. Demographic characteristics of 161-km ultramarathon runners. Res Sports Med. 2012;20:59-69.

203. Nikolaidis PT, Cuk I, Clemente-Suárez VJ, Villiger E, Knechtle B. Number of finishers and performance of age group women and men in long-distance running: comparison among $10 \mathrm{~km}$, half-marathon and marathon races in Oslo. Res Sports Med. 2021;29:56-66.

204. Nuzzo J. Volunteer bias and female participation in exercise and sports science research. Quest. 2021;73:82-101.

205. Hagstrom AD, Yuwono N, Warton K, Ford CE. Sex bias in cohorts included in sports medicine research. Sports Med. 2021;51:799-804.

206. Tiller NB, Roberts JD, Beasley L, Chapman S, Pinto JM, Smith L, et al. International Society of Sports Nutrition Position Stand: nutritional considerations for single-stage ultra-marathon training and racing. J Int Soc Sports Nutr. 2019;16:50.

207. Mountjoy M, Sundgot-Borgen JK, Burke LM, Ackerman KE, Blauwet $\mathrm{C}$, Constantini N, et al. IOC consensus statement on relative energy deficiency in sport (RED-S): 2018 update. Br J Sports Med. 2018;52:687-97.

208. Riggs BL. The mechanisms of estrogen regulation of bone resorption. J Clin Investig. 2000;106:1203-4.

209. Chen Y-T, Tenforde AS, Fredericson M. Update on stress fractures in female athletes: epidemiology, treatment, and prevention. Curr Rev Musculoskelet Med. 2013;6:173-81. 
210. Papageorgiou M, Elliott-Sale KJ, Parsons A, Tang JCY, Greeves JP, Fraser WD, et al. Effects of reduced energy availability on bone metabolism in women and men. Bone. 2017;105:191-9.

211. Knechtle B, Nikolaidis PT. Physiology and pathophysiology in ultra-marathon running. Front Physiol. 2018;9:634.

212. Ji M-X, Yu Q. Primary osteoporosis in postmenopausal women. Chronic Dis Transl Med. 2015;1:9-13.

213. Hew-Butler T, Rosner MH, Fowkes-Godek S, Dugas JP, Hoffman $\mathrm{MD}$, Lewis DP, et al. Statement of the 3rd international exerciseassociated hyponatremia consensus development conference, Carlsbad, California, 2015. Br J Sports Med. 2015;49:1432-46.

214. Hoffman MD. Preventing casualties in ultramarathons. Sports Med. 2021;51:1599-600.
215. Wieringa FP, Broers NJH, Kooman JP, Van Der Sande FM, Van Hoof C. Wearable sensors: can they benefit patients with chronic kidney disease? Expert Rev Med Devices. 2017;14:505-19.

216. Rojas-Valverde D, Sánchez-Ureña B, Pino-Ortega J, Gómez-Carmona C, Gutiérrez-Vargas R, Timón R, et al. External workload indicators of muscle and kidney mechanical injury in endurance trail running. Int J Environ Res Public Health. 2019;16:3909.

217. Beunders R, Struck J, Wu AHB, Zarbock A, Di Somma S, Mehta $\mathrm{RL}$, et al. Proenkephalin (PENK) as a novel biomarker for kidney function. J Appl Lab Med AACC Publ. 2017;2:400-12.

218. Beker BM, Corleto MG, Fieiras C, Musso CG. Novel acute kidney injury biomarkers: their characteristics, utility and concerns. Int Urol Nephrol. 2018;50:705-13.

\section{Authors and Affiliations}

\section{Volker Scheer $^{1} \mathbb{D} \cdot$ Nicholas B. Tiller $^{2} \mathbb{D} \cdot$ Stéphane Doutreleau $^{3}$ (D) Morteza Khodaee ${ }^{4} \cdot$ Beat Knechtle $^{5,6}$ (ID) Andrew Pasternak ${ }^{7,8}$ (D) Daniel Rojas-Valverde ${ }^{9}$ (D)}

1 Ultra Sports Science Foundation, 109 Boulevard de l'Europe, 69310 Pierre-Benite, France

2 Institute of Respiratory Medicine and Exercise Physiology, Lundquist Institute for Biomedical Innovation at Harbor-UCLA Medical Centre, Torrance, CA, USA

3 Sports Medical Unit, HP2 Laboratory, Univ. Grenoble Alpes, Inserm, CHU Grenoble Alpes, Grenoble, France

4 Department of Family Medicine and Orthopedics, Division of Sports Medicine, University of Colorado School of Medicine, Denver, CO, USA

5 Medbase St. Gallen Am Vadianplatz, St. Gallen, Switzerland
6 Institute of Primary Care, University of Zurich, Zurich, Switzerland

7 Silver Sage Sports and Fitness Lab, Reno, NV, USA

8 Department of Family and Community Medicine, University of Nevada Reno School of Medicine, Reno, NV, USA

9 Centro de Investigación y Diagnóstico en Salud y Deporte (CIDISAD), Escuela Ciencias del Movimiento Humano y Calidad de Vida (CIEMHCAVI), Universidad Nacional, Heredia, Costa Rica 